\title{
Nursing: Is it a Co-dependent Culture?
}

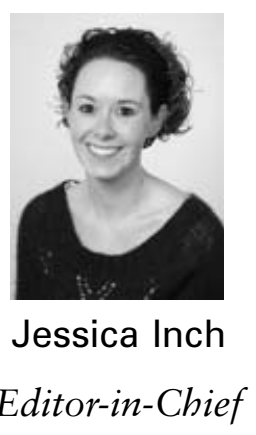

$\mathrm{T}$ There exists a theory that says nurses are firmly fixed within a culture of co-dependency, in terms of both behaviour and the organisation in which they work. This has been supported by many of the lectures I have attended over the last year. If this theory is correct, what does it mean for the progression of nursing, not just in the peri-operative field, but throughout the NHS?

The idea of co-dependency in nursing is not a new one and is undoubtedly controversial. This is the idea that the nurse is actually dependent on the patient, with the theory of co-dependency being characterised by one's dependence on an external source for self-worth and self-definition. This theory then goes further to suggest that nursing as a profession is co-dependent, working within its confines and limited by its disempowerment.

As you will hear from some of this journal's conference reports regarding lectures attended this year both in this country and further afield, nursing as a profession is hindered by its historical routes, culture and professional relationships. BARNA's Annual Conference was opened by Eileen Sills; Chief Nursing Officer for Guys and St Thomas NHS Trust, who challenged our attitudes towards the expansion of our duties and the changes forced upon us, asking us to take responsibility for our own future. This was then examined from a different angle by BARNA's President
Mark Radford. Mark's closing speech 'Anyone for Tennis' centred round the games that doctors and nurses play when planning patient care and how this serves to keep nurses in their place'. This was continued with a session by Joni Brady; International Representative and Sue Fossum; Immediate Past President of ASPAN who also urged us to find our political voices and change things for ourselves.

When attending the American Society of PeriAnaesthesia Nurses Conference this year, I also got a chance to listen to Suzanne Gordon's opening speech entitled 'From Silence to Voice'. Here I learnt more about the history of nursing, and how it originally was undertaken by nuns who characteristically gave themselves over to the role entirely. Many believe that this history has had a lasting effect on the constraints of the profession despite its ever-changing roles, leading to a co-dependent profession.

What I have listened to this year has made a lot of sense to me and offered an explanation as to why so many of us leave the implementation of change to the politicians, and then complain about the choices made for us. This is clear co-dependent behaviour, and it is time to act on our own behalves. Until nursing is practiced in this balanced active way and accepted as such within the culture and organisation of the NHS, we will continue to be powerless in shaping our own practice and future. 